Author: Ruez Derek."I never felt targeted as an Asian... until I went to a gay pub" : Sexual racism and the aesthetic geographies of the bad encounter. Environment and Planning A. 2017,49,4,pp. 893-910. Copyright (C) 2017 The Author(s). Reprinted by permission of SAGE Publications. DOI:10.1177/0308518X16680817.

\title{
'I never felt targeted as an Asian...until I went to a gay pub': Sexual racism and the aesthetic geographies of the bad encounter
}

Derek Ruez

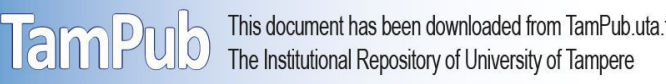

University of Kentucky

817 Patterson Office Tower

Lexington, KY 40506

dmruez@gmail.com

\begin{abstract}
:
Encounters across difference-in city spaces marked by diverse migration trajectories, cultural differences, and racialized hierarchies - have captured the attention of urban scholars concerned with both the challenge of "living with difference" and the promise of multicultural conviviality that inhere in the super-diversity of many cities. Expanding on approaches that focus on analyzing the conditions of a good or "meaningful" encounter that can reduce prejudice or promote intercultural understanding, this paper brings interviews with queer Asian men in Sydney, Australia into dialogue with Sara Ahmed's revaluation of the "bad encounter." It shows how research on encounters can more productively engage with how negative encounters can become meaningful political occasions in their own right. Focusing on the problem of sexual racism as it emerges in accounts shared by participants, the paper highlights dating and sex as important moments through which the aesthetic orderings of race, gender, and sexuality shape the unevenly shared spaces of citizenship and urban life.
\end{abstract}

Keywords: Spaces of encounter, sexual racism, migration, urban diversity

This is a post-print version for institutional archiving. The final version is available as:

Ruez, D. (2017) 'I never felt targeted as an Asian... until I went to a gay pub': Sexual racism and the aesthetic geographies of the bad encounter. Environment and Planning A 49(4): 893-910. 
Encounters across difference-in urban spaces marked by diverse migration trajectories, cultural differences, and racialized hierarchies_-have captured the attention of many scholars concerned with both the challenge of "living with difference" and the promise of multicultural conviviality that inhere in the super-diversity of contemporary urban life (Amin, 2002; Nagel and Hopkins, 2010; Valentine, 2008; Vertovec, 2007). Drawing on interviews with queer Asian men in Sydney, as well as archival evidence of political projects and cultural production, this paper contributes to these literatures through examining accounts of dating and sex as important moments of encounter through which the aesthetic orderings of race, gender, citizenship, and belonging are constituted. However, in distinction—but not opposition — to approaches that focus on analyzing or clarifying the conditions of a "good" or "meaningful" encounter that can reduce prejudice or promote intercultural understanding (Matejskova and Leitner, 2011; Mayblin et al., 2015; Wilson, 2013), I mobilize Ahmed's (2010) revaluation of the "bad encounter" by attending specifically to the problem of sexual racism as it emerges in the accounts shared by participants.

To be sure, sexual encounters certainly can produce spaces in which prejudices can be challenged and relationships across difference forged (Delaney, 1999), but more common, in this research, were accounts of racialized exclusion and (micro)aggression, or what a number of participants identified as sexual racism, where racialized sexual "preferences" devalued participants and limited their erotic options (Callander et al., 2012; Caluya, 2006). Adopting an aesthetic approach to the politics of sexual racism, this paper focuses on the sense that is made of encounters with racializing dispositions and practices. Thus, I am concerned with "forms of perceiving the world and modes of relating to it" as they shape and are shaped by intimate encounters with sexual racism and their aftermaths and elsewheres (Dikeç, 2015: 1). This aesthetic approach to politics is one in which the sharing and partitioning of space are central (Rancière, 2010), even as aesthetics' conventional reference to beauty and taste are not irrelevant to the problem of sexual racism and the gendered and 
racialized experiences of attractiveness at work there (cf. La Fountain-Stokes, 2011).

This particular focus on the "bad encounter" of sexual racism—distinct from the important work that has been done to challenge overly optimistic readings of encounters across difference (Hopkins, 2014; Valentine, 2008) — is about opening up the literatures on spaces of encounters to understanding "how bad feelings are not simply reactive; they are creative responses to histories that are unfinished" (Ahmed, 2010: 217). That is to say, bad encounters are not only counterfactuals to be posed to more optimistic accounts, nor are they simply negative moments to be overcome in the search for "meaningful" encounters. Instead, bad encounters have a life and a politics of their own. Approaching the intertwining of sex and sense in accounts of encounters with sexual racism can help move literatures on urban encounters across difference beyond a moral lens of reducing prejudice and toward an engagement with the ambivalent politics of encounter in the unevenly shared spaces of urban life.

Before turning to the study and its findings, I first outline some of the key contributions of literatures on encounters across difference and suggest how attending to the politics of "bad encounters" can productively extend that work. Next, I highlight the importance of sex and dating as sites of encounters and as moments through which the geographies of race, gender, and sexuality are constituted in everyday urban life. Finally, I elaborate the aesthetic approach to politics developed in this paper, with its emphasis on making sense and sharing space across the plural and uneven geographies of contemporary cities.

\section{Opening up the bad encounter}

Cities are frequently understood as important sites in the coming-together of difference (Fincher and Jacobs, 1998; Sandercock, 2003). Indeed, in the everyday conviviality of multicultural urban life, a number of scholars have found a hopeful model of engagement across difference and 
suggest that such interactions can provide a foundation for creating more inclusive social relations (Amin, 2002; Laurier and Philo, 2006; Wise, 2005). Raising some critical questions about the idea that encounters across difference will tend to erode prejudice or exclusion, Valentine (2008) makes a compelling case for a more complicated understanding of encounters across difference that takes seriously the ways that encounters may reinforce prejudice and other exclusionary tendencies. This involved a critical geographic engagement with the "contact hypothesis" and challenging simplistic understandings that contact across difference would necessarily lead to reducing the prejudices of those involved (also see Matejskova and Leitner, 2011). ${ }^{1}$ Much additional work has gone into examining the spatialities of encounters and the conditions under which these encounters could have meaningful effects in challenging prejudices or promoting intercultural understanding (Leitner, 2012; Mayblin et al., 2015; Wilson, 2013). Thus, while significant threads of this work have sought to show the promise of encounters for reducing prejudice and achieving better relations (variously defined), others remind that there is nothing necessarily liberating about encounters, and that these encounters may work to reinforce prejudices and reinscribe exclusion (Hopkins, 2014; Noble and Poynting, 2010). In one sense, then, the possibility of bad encounters has been central to these literatures for some time. Yet, the goal, even in work that emphasizes the potential downsides of encounter, has generally remained oriented toward the pursuit of better encounters that could more effectively reduce prejudice. In the process, the productivity of negative encounters has remained underexamined.

It is here that Ahmed's (2010) revaluation of the "bad encounter" offers a useful framework for extending urban scholarship on encounters across difference. In the conclusion to The Promise of Happiness, Ahmed mounts a critical reading of what she calls the "affirmative turn" in philosophy and social theory. Ahmed develops her argument in relation to a lecture on Spinoza delivered by Deleuze (1978) where he contrasts a "good encounter," exemplified by eating something 
pleasurable, with a "bad encounter," exemplified by eating something poisonous: "For Deleuze the good encounter increases the capacity for action: we could describe the good encounter as the agreeable effects of agreement" (Ahmed, 2010: 211). For scholars working in the affirmative mode, such good encounters are purposefully privileged as generative sites and openings into new futures. Bad encounters, in contrast, are often understood as "black holes," blockages that close off possibility (Braidotti, 2006: 247). It is this association of the good encounter with generativity and openness and of the bad encounter with passivity and closure that draws Ahmed's critique. The point here is not to attack this "affirmative turn" tout court, but to argue that bad encounters are not necessarily passive moments of closure: "we cannot know in advance what different affects will do to the body before we are affected in this or that way" (Ahmed, 2010: 215).

As an intervention in social theory and philosophy, revaluing the "bad encounter" has important insights to offer to our understandings of sexual racism and empirical scholarship on encounters across difference. Building on Wilson's (2016) argument about the importance of understanding the multifaceted ways that encounters may be "meaningful," I examine the bad encounter of sexual racism in order to show how participants "learn from blockages" (Ahmed, 2010: 215) and develop response-both quotidian and more organized — to encounters with racializing dispositions and practices.

\section{Sex as site of encounter}

Researchers have examined encounters across difference in a number of different spatial contexts, including urban public spaces like city streets (Wise, 2005) and public transport (Lobo, 2014a; Wilson, 2011), as well as schools (Hemming, 2011; Wilson, 2014), university campuses (Andersson et al., 2012), places of worship (Ehrkamp and Nagel, 2012), within families (Valentine et al., 2015), in homes (Schuermans, 2013), and in organized activities and community projects 
(Matejskova and Leitner, 2011; Mayblin et al., 2016; Wilson, 2013). Further, literatures on spaces of encounter have expanded beyond a focus on encounters across ethnic, racial, and/or cultural difference in diverse urban spaces of migrant settlement to a broader range of differences, including work on cross-class encounters (Lawson and Elwood, 2014), calls for more intersectional approaches to encounter (Valentine and Waite, 2012), and accounts of encounter beyond the dynamics of "Western" cities that highlight the necessarily situated character of encounters and their study (Ye, 2016a).

However, there remains a need to better understand dating and sex as significant moments of encounter across racialized difference in context of urban diversity and migrant settlement. To be sure, there has been important research both on encounters across sexual identities_-as in Andersson and colleagues' (2011) examination of encounter between straight-identified members of a New York City church and the city's queer communities (also see Gorman-Murray and Waitt, 2009)_ and, more generally, a productive proliferation of scholarship on the intersection of sexuality and race in and beyond geography (for a review, see Brown, 2012), but dating and sex as sites of encounter remain relatively underexplored. Thus, this paper extends Noble and Tabar's (2014) argument about the importance of sex in the process of migrant settlement by highlighting the particular experiences of queer migrants in Sydney and what can be learned about the aesthetic coordinates of citizenship through participants' experiences with dating and sex in Sydney.

That these experiences are racialized and inflected with hegemonic masculinities is not surprising. Caluya (2006; 2008) and Raj (2011) have both offered powerful ethnographic accounts of sexual racism in Australia that have explored how racialized sexual preferences and discriminatory actions during potential encounters have shaped queer scene and online spaces, and the widespread presence of racially discriminatory language on dating sites and hook-up apps has also been well documented (Callander et al., 2012; Riggs, 2013). Discussions of sexual racism in Sydney are 
necessarily bound up with political and economic shifts in Australia's relationship to "Asia” (Ang, 2016) and racializing orderings through which white settler Australia experienced itself in opposition to their proximate neighbors (Hage, 1998). For queer Asian men in Sydney, these dynamics intersect with a partial and uneven valorization of otherwise marginalized queer identities (Nicoll, 2002) and the continuing power of normative masculinities to shape identities and organize encounters across difference (Berg and Longhurst, 2003; Gorman-Murray and Hopkins, 2014; Hopkins and Noble, 2009). This is important not just because sexual racism is itself pernicious and an obstacle to belonging and participation—although it is—but also because these coordinates have broader effects that shape intersecting processes of racialization, migrant settlement, and urban life.

\section{The aesthetic politics of encounter}

Encounters have attracted attention, in part, because of their potential to exceed or complicate the coordinates of dominant discourses. So for example, in the contexts of public debates dominated by pronouncements of the failures of multiculturalism, attention to everyday multicultural conviviality provided a more complex counterpoint (Nagel and Hopkins, 2010; Wise and Velayutham, 2009). Moments of encounter have also been investigated by scholars interested in the affective and material nature of sociality (Brown, 2008; Nayak, 2010). In this vein, researchers have approached encounters as sites of emergence through which, for example, race-rather than only being a set of symbolic coordinates shaping encounters in advance-actually emerges out of the encounter itself (Lim, 2010; Saldanha, 2007; Slocum, 2008). This opens up attention to race as an assemblage that exceeds the a priori coordinates of skin color or cultural racism, attends to multiple materialities of encounter, and highlights the non- or preconscious operations of differentiation (Swanton, 2010a). Read in this way, encounters are events through which people, spaces, categories, and materials stick together in particular ways. 
Despite this productive emphasis on the moment of encounter itself, it is also important to note that encounters have a history (Swanton, 2010b) and a future, in the sense of orienting action and movement toward future encounters (Ahmed, 2006). In exploring the openings of the bad encounter, my approach is indebted to Valentine and Sadgrove's (2012, 2014) exploration of how participants narrate and explain encounter after the fact. However, rather than focusing on individuals' moral dispositions toward difference, as they do, I develop an account of how participants made sense of experiences of sexual racism that locates the question of encounters across difference within an explicitly political framework that understands the city as an unevenly shared space—simultaneously riven and ordered by the material and normative force of race, sexuality, and gender. This approach builds on the work that has sought to carve out an aesthetic account of politics, where the aesthetic reference is extended from questions of beauty or taste to broader questions of sense and space (Dikeç, 2015; Kallio, 2012; Marshall, 2013).

Productive work has explored how sensations experienced within queer spaces "produce embodied emotions of attraction, disgust, arousal, identity, (dis)connectivity and belonging" (Taylor and Falconer, 2015: 45; also see Nash and Bain 2007; Waitt and Johnson, 2013) and recent work has highlighted the sensuousness of migrant settlement (Lobo, 2014b; Wise, 2010). These aesthetic forms and modes of relation give space to encounters, even as encounters themselves can shift, disrupt, or reinforce these coordinates. Here, Rancière's (2010: 36) writing on the "partition of the sensible" offers a suggestive way to understand how encounters take place within an aesthetic ordering that shapes "the relationship between a shared common and the distribution of exclusive parts... in sensory experience." What I take from Rancière here is less a specific conceptualization of politics and more his attention to the connection between sense, space, and the common of a community, including the dual nature of this partitioning (partage) involving both the sharing of space and its division_ of partitioning and partaking in (cf. Panagia, 2010). 
The simultaneously shared and divided spaces of the city represent an important political site, and sex is one important aspect of the unevenly shared spaces of urban life. To say that space is shared is not to subscribe to a communitarian imagining of commonality or to endorse a falsely universalized public sphere, but instead to emphasize how the co-presence of plural projects and actors together in the city necessitate politics (cf. Ferguson, 2012; Ruez, 2016). Further, as Catungal (2013) reminds us, underneath the promise of the "global-multicultural city" are exclusions and violence that create an uneven geography of belonging and citizenship (also see Manalansan, 2005). These uneven geographies can be understood, following Ahmed (2006), to orient people and spaces in certain ways and to produce particular kinds of trajectories and, thus, particular kinds of encounter in the city. It is my hope that attending to the aesthetic orderings of sexual racism can help to nudge literatures on urban diversity and encounter toward a more explicitly political engagement with these uneven geographies and differentiated trajectories.

\section{Study and methods}

This paper emerges from a broader research project examining the mutually constitutive relationship of sexuality and race in the urban politics of migration and citizenship in Sydney, where over 32\% of Greater Sydney's population were born outside Australia, and nearly $57 \%$ of population report having one or more parents who were born outside Australia (Australian Bureau of Statistics [ABS], 2011). This project draws on a set of interviews with 43 queer migrants and Australian-born adult children of migrants_conducted between 2012 and $2013 .^{2}$ While eschewing a generational model of immigrant incorporation, examining the experiences of those who themselves had migrated (some recently, some long settled) as well as those whose parents had migrated allowed an exploration of these longer term politics of migration and citizenship (cf. Kobayashi and Preston, 2014). These were semi-structured conversations that explored participants' histories of 
migration and settlement, the spatialities of everyday life in Sydney, and relationships with queer and ethnic communities in the city. Focusing on a subset of these interviews, this paper examines the accounts that emerged from interviews with queer Asian men in order to better understand the complicated intersection of sexuality, race, and gender at work in discussions of sexual racism. ${ }^{3} \mathrm{In}-$ depth interviews provided the opportunity_following Valentine and Sadgrove (2012, 2014)— to examine how participants narrate these encounters in the sense of integrating them into their accounts of themselves, their relationships, and their political projects. During the course of my fieldwork, I also collected and analyzed an archive of materials related to the politics of race and sexuality in Sydney—-some of which supplements the analysis here. Interview transcripts and other materials were analyzed through a formal process of coding and theme building to help identify categories and patterns in the data (Cope, 2010), and I approached this analysis with both a phenomenological attention to the textures of everyday life in participants' accounts (Hitchings, 2012) and an attention to participants' statements as discourse (Secor, 2010).

Even as this paper intervenes in discussions about migration-led diversification of city spaces and the social and political possibilities that ensue, it is important to note that, for those who have at one point migrated from one country to another, as well as those born in Australia whose parents had migrated — being understood as a "migrant" is not necessarily always the most salient feature of their identities (Rogaly, 2015), and, in a racializing context, the label of migrant may cling more resolutely to some than others and may work to place one's citizenship or belonging in question. Thus, this paper follows recent efforts to recontextualize migration—away from seeing migrants as disruptions to otherwise static polities and toward a broader understanding of society as constituted through and by a variety of movements and mobilities (Hall, 2015). Such an approach is necessary for understanding how "the everyday translocal and inter-cultural experience of Asianheritage migrants in Australia_-which constitutes Australian social life as translocal and inter- 
cultural — underlines the fallacy of conceiving of 'Asia' and 'Australia' as radically separate or separable entities" (Martin et al., 2015: 6). In the analysis that follows, I employ the categories, such as Asian, or, for that matter, queer or gay, that have shaped aesthetic orderings in Australia and, more importantly, that participants used as self-identifiers (cf. Wong, 2015). However, rather than demographic descriptions, these terms and their sense should be seen as the contingent and provisional outcome of relational processes of becoming such as those described by participants as they recount encounters (Slocum, 2008).

\section{Making sense of sexual racism}

Participants' accounts of sexual racism echoed many of the kinds of experiences that have been examined elsewhere (Ayres, 1999; Caluya, 2006; Raj, 2011; Ridge et al., 1999). They noted encounters with racist language on hook-up apps like Grindr, as well as micro and macro aggressions when on dates, when attempting to flirt in a bar, or when seeking a partner in a sex-onpremises venue. These were encounters - either by virtue of their exceptionality in comparison to other experiences in Sydney or because of their persisting frequency and regularity — that participants frequently described as important to their sense of who they were, where they were at, and where they did or did not belong. They described these experiences as obstacles to particular desired encounters, as an affront to participants' "self-image," and as a barrier to inclusion within queer spaces. This paper launches off from those concerns in order develop a political analysis of what happens elsewhere and after these encounters with racializing dispositions and practices. Given the importance of sexuality to public life and the importance of sex to queer public cultures in particular, this particular manifestation of racialized devaluation raises important political questions

about how spaces of the city are shared and divided, and it points to the intimate, embodied, and sensuous politics of urban encounters. To tease out these questions, I turn to a story shared by 
Mark, a gay Malaysian Australian man in his late 20s:

I was at a foam party, and I was making out with some guy and having a good time and his friends had been looking for him, and they came back to find him and... they basically looked at me-so, they found him and saw that he was making out with someone and, then they decided to make quite horrible racist remarks about me-to the effect of 'why on earth are you making out with him, you know... the Asian guy... couldn't you do better?'

What is described as a pleasurable encounter, "making out... and having a good time," is interrupted in a way that shocks and, ultimately, shames with the overheard questions: "couldn't you do better?"

I was so shocked, and he actually didn't say anything-now, I don't know how drunk or whatever he was but he didn't say anything — and I was just so shocked. I just pulled away, and I disappeared into the back of the crowd, and I actually felt, apart from the shock, I actually felt ashamed to be there at that point, and I was like, my God, I can't believe someone actually said that, and I actually feel horrible to the point where I need to hide now. And I actually felt shame at that point, and it was just the most strange and yucky feeling... so that was pretty shocking to me and painful and hurtful.

That sense of shock and shame at experiences of sexual racism was shared in a number of interviews, and it has been pointed to in Caluya's (2006) work on sexual racism. Mark would further explain the "shock" he experienced in relation to having "never felt targeted as an Asian... ever... until I went to a gay pub.” This clashed with the expectations he would articulate of gay spaces where individuals, by virtue of their disadvantaged place in normative hierarchies of sexuality, ought to have been more attuned the damaging effects of such exclusions and devaluations:

I thought this was a gay club and, you know, if anyone should understand discrimination, it should be here... evidently no.

It should be noted that these are queer spaces that were also not infrequently discussed as havens from heteronormative expectations elsewhere in their lives, and, for some, the ability to openly access such spaces figured as an important element in their decisions to migrate to or remain in Australia. Precisely for those reasons, the disappointment and exclusions occasioned by sexual racism may be all the more keenly felt.

Mark's story is exemplary, in many ways, of the kinds of experiences that participants 
described. More broadly, in the context of dominant forms of gay racialized masculinity, many of those interviewed expressed feeling disadvantaged in the erotic economies of queer spaces. Marvin, a student in his early 20s from the Philippines, discussed his take on the problem:

There are so many stereotypes. The way they see Asians as feminine, passive, always a bottom. It can really limit you. Even if you're those things... People don't see you outside of those things. So they either like you or they don't, you know, but not for who you really are.

Not being seen for "who you really are," was a not uncommon trope for describing the damage of encounters with sexual racism. Others discussed the related problem of being "fetishized" as Asian in similar terms, where, even to the extent that one identified as feminine or a bottom and where those qualities were sought out by others, there was a danger of being reduced to those qualities and being understood only through those qualities.

Reflecting on the aesthetic orderings that shaped these encounters, a Malaysian Australian man in his 50s who migrated to Australia in the early 1980s, Jun described what he came to understand as a hierarchy of attractiveness tied to one's position in broader social hierarchies:

I think another mark of status is whether you come from that country that's progressive in terms of its gay politics. So you come from a country where the gay politics are not progressive then your status is lower.

This implies the existence of a sensed geography of "progressiveness" in relation to sexuality that is necessarily implicated in a racializing aesthetic order. This racializing order, of course, makes unnecessary much substantive knowledge about the state of "gay politics" in a variety of countries that would seem to be presumed by that statement, and it also renders superfluous concrete knowledge of a particular person's country of origin or migration trajectory. Instead this is a sensed status that emerged out of a complicated and spatially contingent collision of categories, subjectivities, and materialities.

The cumulative effects of bumping up against these orderings over time could be significant, as Jun discussed: 
I had been traumatized by it you know like over a period of 30 years. It's a slow sort of trauma, like you get rejected bit-by-bit you know, month after month, slowly and then you try to reconcile that, and you can never do that. And then, yeah I find I built a kind of resistance to it. But I'm aware that, for example, out in the gay scene, there will be some people who will never be interested in me because they are very white, and they're very into whatever they are into... I think it's very traumatizing.... And we're not talking like just a few people. It's like most of the people.

Here, rather than the shock and surprise of Mark's account, we see a "bit-by-bit" rejection described by someone who had migrated to Sydney as a young adult in the early 1980s. He was not the only interviewee to invoke a language of trauma to describe experiences with sexual racism, and that these experiences are detrimental, and, for some, exceedingly so, was borne out time and again in participants' narratives.

Of course, encounters necessarily take on spatially contingent forms (Leitner, 2012) and the contingencies of sharing space with others can lead to unexpected outcomes (Caluya, 2008). Participants explained important differences in spatial contexts where, for example, the distanciated and partially anonymous spaces of hook-up apps seemed to facilitate particularly open forms of racism or, where, in the face-to-face intimacy of sex-on-premises venues, sensed sexual attraction seemed to overpower social conventions of conviviality that marked more diverse-use leisure spaces. Some interviewees described scene spaces on Oxford Street, the center of Sydney's traditional "gayborhood," as suspect in fairly general terms, while others noted a complicated geography of welcoming and unwelcoming spaces there (cf. Waitt, 2006). For some interviewees, these spaces were seen as sites of exclusion or violence. Participants also identified particular bars that were known as places where gay Asian men and their admirers were likely to congregate. While some described them as comfortable or pleasurable sites, others discussed them as places to avoid— to avoid being fetishized or, for some, to assert their difference from other gay Asian men. Some also expressed feeling more comfortable in queer-friendly, but mixed venues_often associated with Sydney's inner west. Others tended not to "go out" in inner Sydney at all, and their social and sexual 
lives revolved around parts of Sydney's western suburbs. These complicated geographies are necessarily bound up with the mobile and shifting urban geographies of queer life in Sydney more broadly (Gorman-Murray and Nash, 2014). At the same time, I think we can also see something like what Kojima (2014) identifies as the basue (outskirts) space-making practices of queer Asian diasporic communities in Vancouver, where queer Asian men's presence on the outskirts of mainstream queer public culture represents, simultaneously, the effects of marginalization and tactical responses to that marginalization. Though participants detailed a range of issues that contributed to a sense of exclusion—from normalizing discourses of "coming out," which some saw as a product of "Western" culture and insufficiently attuned to the complexities of their lives, to economic constraints that limited some participants' access to scene spaces to under-representation in queer community organizations_-sexual racism was a frequently cited as a cause for a felt sense of marginalization and exclusion, and it motivated a variety of responses with complicated relationships to the centers and margins of queer urban life in Sydney.

\section{Encountering politics}

Thus, the bad encounter with racializing dispositions and practices is not the end of the story. Sara Ahmed encourages us to see such encounters as, at least potentially, an opening for politics rather than something to be read over in search of a better encounter, and participants' responses to experiences of sexual racism bear this out. Similarly, Caluya (2006) argues for the importance of attending to the productivity of the shame produced through sexual racism. Specifically, Caluya is interested in understanding what the shame of sexual racism produces at the level of subjectivity. Extending Caluya's point, in the following section, I trace out some of the ways_-both quotidian and more organized — that participants responded politically to experiences of sexual racism. The point is not that these bad encounters necessarily produce a political response in 
some kind of automatic way, nor that encounters need be read in a prescriptive manner (cf. Ye,

2016b) but rather, to show how the bad encounter of sexual racism can lead to new openings and orientations.

Mark, whose experience at the foam party opened the previous section, credits that incident with heightening his awareness of anti-Asian sentiment in scene spaces:

So then I began to pick up-going to other clubs with other friends and, I pick up other things- people walk into a club and, give remarks just in general, like oh my gosh, "why did you bring me here," you know, "there's so many Asians, can we go somewhere else?" That was... I had never heard that before. So I guess, my eyes did open a little bit and made me be a bit more street savvy I guess, which was disappointing.

In response to the experience, Mark describes how his "eyes did open a little bit," and he began to notice times and places where the racializing orders shaping queer life were manifested. The disappointment mentioned here, I would suggest, registers as a lack of happiness with these orders and a refusal to accept their coordinates. Mark continues:

At the same time, I met some of the most wonderful people. You know, I think I, like any community, I've met the best of the crowd and maybe- hopefully not - the worst, and, dare I say some of them are my friends; you know like they might say something inadvertently and they don't see me as Asian particularly but, they might say something and, then I'd be like "really did you just say that? I can't believe you just said", and I picked them up on it.

Here, we see the encounter with sexual racism at the foam party, necessarily embodied and affective, that is assigned particular kinds of meaning and becomes the basis for noticing different things, acting in different ways, and bringing others around to noticing and responding differently to racialized orderings.

This process of making sense often led beyond the immediate context of the encounter itself. Here, John, another gay man who migrated to Sydney from Malaysia, points to media representations that shaped the aesthetic coordinates that gave form to the kinds of encounters that participants described:

I place a lot of blame on the gay media here.. .. Not so much the SSO [Sydney Star Observer] 
because they're more of the newspaper, but with $S X$, I do. They're the one that always have a hot model on the cover. They're always Caucasian... We asked him [the editor], why don't you ever have Asian models, and not just Asian models, but black models, or whatever. He said it just didn't sell. People wouldn't pick it up. And to a certain extent, ok, I can see that, but I just feel that you are forming public opinion and therefore you have a responsibility to do something about it.

Participants articulated critiques of the local gay media, but also of national and international media-both gay and mainstream. They discussed the relative invisibility of gay Asian men and of the limited or "stereotypical" visibility of Asian people more broadly (cf. Eng, 2001; Fung, 1991). Implicitly or explicitly, a number of participants articulated political claims that media outlets and gatekeepers "have a responsibility to do something about" problematic or absent representations that contribute to creating an aesthetic order that devalues gay Asian men.

A number of people I interviewed were involved in projects seeking to challenge sexual racism, particularly in forms of online writing and social media work. A project called Sexual Racism Sux, led by Andy Quan and Tim Mansfield, is one particularly important example, and its web and social media presence should be credited with helping to popularize the term sexual racism in Australia. Conceived as an opportunity to confront "racist behaviour and speech in gay men," it encouraged people "to reflect on patterns in your own behaviour and what that might reveal to you about what's going on inside you," and start conversations about the impact of openly expressed racial preferences and racist language on gay dating profiles (Sexual Racism Sux, n.d.):

Sexual behaviour is no more justified a place for racial prejudice than any other area of life. We don't consider it racist to not want to sleep with men of specific races. Boring, perhaps, but not racist. But people can express that preference in racist and unwelcoming ways. That's what we're against. (Sexual Racism Sux, n.d.)

As Quan suggests in a published interview: "We weren't focused on getting rid of all sexual racism in the world. We really just focused on: 'How can we get the gay internet sites... to be less racist and more open?"' (Woo, 2008: np). Much of the focus on challenging sexual racism has shifted to social media and to the racism visible on hook-up apps like Grindr, but I cite Quan's quote to highlight 
the modest but important goals of creating a "less racist and more open" online dating environment.

Another project, centered on creating a glossy magazine called $A-M e n$, takes the response to sexual racism in a slightly different direction. Published by the AIDS Council of New South Wales and edited by Min Fuh Teh (2012), the magazine features interviews, essays, poetry, and photographs of gay Asian men. Beyond the stance of encouraging people to reflect on their preferences and change their public expression that characterized Sexual Racism Sux, $A-M e n$ is, among other things, meant more directly as an intervention into the aesthetic orders that devalue gay Asian men. Specifically, the photographs, featuring shirtless, "active," "gym-toned" bodies were intended to show that gay Asian men can be "masculine" and attractive in the same ways as anybody else (see Figure 1). This was meant, at least in part, as a corrective to the problem of invisibility noted earlier, and as a way for gay Asian men to be able to see themselves reflected back positively within the confines of existing aesthetic orders. Those involved with the project also hoped that the images would catch potential readers' attention to a broader range of issues, including sexual racism, but also discussions of "coming out," identity and migration, and sexual health. Caluya (2006) and Nguyen (2014), among others, have raised important questions about the viability of a "politics of visibility" seeking to reassert a masculine Asian identity within the confines of existing aesthetic orders, and participants in the project themselves raised some similar issues, including skepticism about whether the images would have the desired impact and concerns that they could reinforce problematic forms of masculinity. At the same time, the A-men project can also be understood as part and parcel of a "racialized body aesthetics" among gay Asian men in Australia analyzed by Yue (2008: 237-238) that "does not simply valorize identity politics; it problematizes how individual and group identities are produced by the dominant and regulatory processes of homogenization, exoticization and incorporation.” There are, of course, strategic and political debates about any project, but my point here is to illustrate how political projects can and do emerge in response to the 
bad encounter.

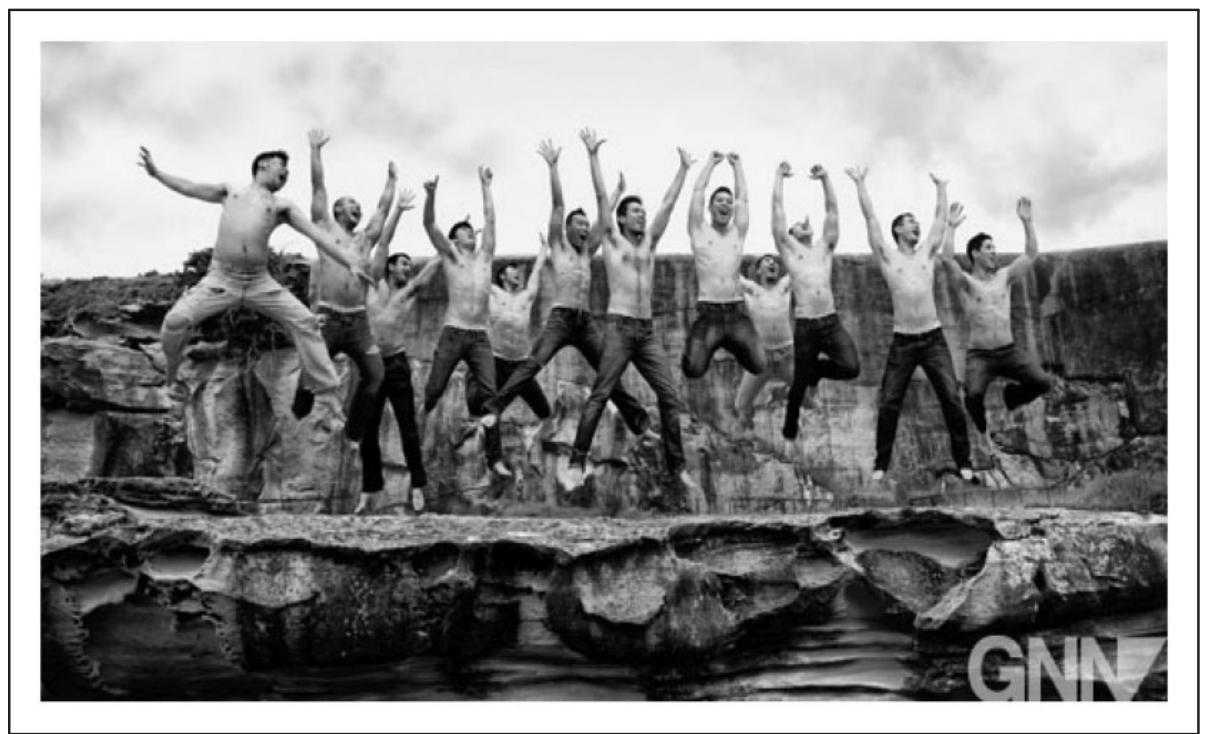

Figure 1. A-Men image. Photo by Simon Le. http://gaynewsnetwork.com.au/feature/a-new-voice4764.html

These political projects represent one way that the impact of encounters with racializing dispositions and practices extends beyond the moment of encounter itself in the way that they reorient participants' attention, trajectories, and projects. This reorientation can itself lead to other encounters. As projects like A-Men and Sexual Racism Sux have brought attention to the problem of sexual racism, this has provoked responses from those who object to problematizing racialized sexual preferences. A frequent objection to the critique of sexual racism is that attraction is something simultaneously personal and immutable. As an exemplar of the kind of response engendered by the naming and critique of sexual racism, Matheson (2012) penned an opinion piece headlined, "I'm a sexual racist" in the Sydney Star Observer. Defending racialized sexual preferences and those who hold them, he writes:

I need to ask though, is that so bad? I mean, I won't have sex with women because I'm gay, but does that make me sexist or a misogynist? It's fair to say that those who put "NO AZNS" on their Grindr profile are being quite antagonistic, insensitive, and should maybe find more articulate ways to express their sexual preferences, but sexual preference of any way, shape or 
form, is something quite personal (Matheson, 2012: np).

Matheson's explanation seeks to re-naturalize sexual racism against its politicization by projects like Sexual Racism Sux. ${ }^{4}$ Specifically, the invocation of the personal here works to remove sexual racism from the realm of shared political engagement. According to this logic, one is simply naturally attracted to whom one is attracted to, and "creating this very negative idea of sexual racism... infringes on our ability to choose who we sleep with without having to feel bad about it" (Matheson, 2012: np). Here we have a demand for a "happier" encounter, hearkening to longstruggled-for freedoms for queer people, that situates critics of sexual racism as "killjoys" (Ahmed, 2010). This may be one area where sexual racism may differ from some of the other kinds of prejudice that the encounter literatures have addressed. To put it a different way, my point is that perhaps these different kinds of prejudice are not actually so different, but that the prejudices of sexual racism may feel differently by virtue of being associated with what is variously understood as the personal, private, or inherent realm of sexual desire. Yet, orientations and attractions are mediated by particular aesthetic orders, and these forms naturalize particular patterns of perception that devalue some as potential sexual partners (and in a host other ways). It is precisely the aesthetic orderings that underlie those "personal preferences" that demand our attention, and, at their best, projects like Sexual Racism Sex and A-Men were able to identify and respond to those orderings.

\section{Following the bad encounter}

This paper's focus on sexual racism was intended to allow an exploration of the aesthetic geographies of sexuality, race, and gender and to facilitate an intervention in the literatures on urban encounters that have tended to overlook the openness of the "bad encounter." It is not meant to suggest that all participants' experiences of sex or dating were uniformly "bad," nor is it a critique of 
affirmative modes of reading, except in the very specific sense outlined by Ahmed. Instead, it has been an attempt to follow the bad encounter of sexual racism where it leads — to shame and exclusion, but also to quotidian responses and organized political projects. Given the central place of sex in a racializing queer public culture, this has particular implications for the queer Asian men I spoke with, but the point raises broader questions about sexual citizenship for others who find themselves devalued in the erotic economies of race (cf. Holland, 2012).

As such, this paper makes a case for the benefits of foregrounding sexuality in discussions of urban diversity and encounters across race and cultural difference. Though questions around sexual identity remain important, the point about sexuality is a broader one, incorporating both sex itself and its politics at the intersection of gender, race, and class (Cohen, 1997; Oswin, 2010). Here, scholarship like Manalansan's (2005) work on the neoliberal politics of queer displacement in New York City, Haritaworn's (2015) exploration of the complicated intersection of racializing xenophobia and queer inclusion in Berlin, Benedicto's (2014) examination of the classed nature of gay life in Manila, and Catungal's (2013) focus on the forms of racialized violence endemic to global-multicultural Toronto, implicitly or explicitly, presents a challenge for work on encounter to more fully engage with the unevenness that characterizes the shared spaces of diverse urban life.

Staying with the "bad encounter" and examining where it leads offers, simultaneously, a critique of the aesthetic orderings shaping encounters and a way to hold out hope for different kinds of encounters, different kinds of cities, and different kinds of worlds. This is not a hope predicated on figuring out how to facilitate particular kinds of good encounters, but instead on the hope implicit in participants' refusal to accept the world as it is (Muñoz, 2009) and grounded in the possibilities and dangers of politics in an unevenly shared world. The quotidian and organized responses to sexual racism recounted by participants here do not overturn dominant orderings in any complete or once-and-for-all way, but they are partial and provisional responses to the bad 
encounter that deserve our attention. Specifically, they point beyond a focus on multicultural

conviviality or on the challenge of living with difference and toward highlighting the differentiated

and differentiating effects of encounters across the uneven geographies of urban life and the always

provisional possibility of politics in response.

\section{Acknowledgements}

This paper would not have been possible without the generous participation of so many people, including those I interviewed most of all. In Sydney, Kevin Bathman opened many a door, and Francis Voon put a roof over my head. I also acknowledge and appreciate funding from the Department of Geography and the Department of Gender and Women's Studies at the University of Kentucky. Srimati Basu, Patricia Ehrkamp, Richard Schein, and Anna Secor provided valuable feedback on the paper, as did the anonymous reviewers. I thank them all.

\section{Notes}

1. Prejudice and its relationship to categorical thinking is clearly an important aspect of sexual racism (Allport, 1954), and it has been an important aspect of the encounter literatures more broadly (cf. Valentine, 2010). My interest in this paper is in the broader aesthetic orders out of which the categories and prejudices of sexual racism emerge insofar as they connect to "race as an embodied and structural system of difference" (Winders and Schein, 2014: 221) that articulates power and difference through the "displacement of difference into hierarchies" (Gilmore, 2002: 16).

2. This included participants from Albania, Bangladesh, Bhutan, Bulgaria, Canada, China, Cyprus, Hong Kong, India, Indonesia, Jordan, Fiji, Malaysia, Lebanon, Pakistan, Palestine, the Philippines, Singapore, Sri Lanka, South Africa, Turkey, and Vietnam, as well as Australian-born individuals. An initial group of participants were recruited from making contact with a variety of queer, multicultural, and queer ethnic organizations in Sydney. Using a process of snowballing (cf. Browne, 2005) from those initial participants expanded the sample to include a broader range of participantsincluding those not already involved with such organizations.

3. My decision to focus on the experiences and narratives of queer Asian men in this paper emerges from both my analysis of the interviews, which showed particular patterns in how queer Asian men were discussing sexual racism in comparison to others (i.e., queer Asian men were, on the whole, much more likely to raise the issue of "sexual racism" and to discuss their encounters with others" racialized sexual "preferences" as being particularly damaging to their sense of belonging in Sydney), as well as my encounter with a variety of political projects that engaged with the problem of sexual racism as it affected queer Asian men specifically.

4. Matheson has since distanced himself from the argument offered in his article. I use it, not with the intention of indicting Matheson personally, but because it is an exemplary articulation of the logics that one encounters when challenging the orderings producing sexual racism. 


\section{References}

ABS (Australian Bureau of Statistics) (2011) Basic community profile: Greater Sydney. Available at: http://www.censusdata.abs.gov.au/census services/getproduct/census/2011/communityprofile/ 1GSYD (accessed 21 October 2016).

Ahmed S (2006) Queer Phenomenology: Orientations, Objects, Others. Durham: Duke University Press.

Ahmed S (2010) The Promise of Happiness. Durham: Duke University Press.

Allport G (1954) The Nature of Prejudice. New York: Perseus Books.

Amin A (2002) Ethnicity and the multicultural city: Living with diversity. Environment and Planning A 34(6): 959-980.

Andersson J, Sadgrove J and Valentine G (2012) Consuming campus: Geographies of encounter at a British university. Social \& Cultural Geography 13(5): 501-515.

Andersson J, Vanderbeck RM, Valentine G, et al. (2011) New York encounters: Religion, sexuality, and the city. Environment and Planning A 43(3): 618-633.

Ang I (2016) At home in Asia? Sydney's Chinatown and Australia's 'Asian century'. International Journal of Cultural Studies 19(3): 257-269.

Ayres T (1999) China doll-the experience of being a gay Chinese Australian. Journal of Homosexuality 36(3-4): 87-97.

Benedicto B (2014) Under Bright Lights: Gay Manila and the Global Scene. Minneapolis: University of Minnesota Press.

Berg L and Longhurst R (2003) Placing masculinities and geography. Gender, Place and Culture 10(4): 351-360.

Braidotti R (2006) Affirmation versus vulnerability: On contemporary ethical debates. Symposium 10(1): 235-254.

Brown G (2008) Ceramics, clothing and other bodies: Affective geographies of homoerotic cruising encounters. Social \& Cultural Geography 9(8): 915-932.

Brown M (2012) Gender and sexuality I: Intersectional anxieties. Progress in Human Geography 36(4): $541-550$.

Browne K (2005) Snowball sampling: Using social networks to research non-heterosexual women. International Journal of Social Research Methodology 8(1): 47-60.

Callander D, Holt M and Newman CE (2012) Just a preference: Racialised language in the sexseeking profiles of gay and bisexual men. Culture, Health \& Sexuality 14(9): 1049-1063. 
Caluya G (2006) The (gay) scene of racism: Face, shame and gay Asian males. Critical Race and Whiteness Studies 2(2): np.

Caluya G (2008) 'The rice steamer': Race, desire and affect in Sydney's gay scene. Australian Geographer 39(3): 283-292.

Catungal JP (2013) Ethno-specific safe houses in the liberal contact zone: Race politics, placemaking and the genealogies of the AIDS sector in global-multicultural Toronto. ACME: $A n$ International E-Journal for Critical Geographies 12(2): 250-278.

Cohen CJ (1997) Punks, bulldaggers, and welfare queens: The radical potential of queer politics?. GLQ: A Journal of Lesbian and Gay Studies 3(4): 437-465.

Cope M (2010) Coding transcripts and diaries. In: Clifford N, French S and Valentine G (eds) Key Methods in Geography. Thousand Oaks: Sage, pp. 440-452.

Delaney S (1999) Time Square Red Times Square Blue. New York: New York University Press.

Deleuze G (1978) Lecture transcripts on Spinoza's concept of affect. Available at: http://www.gold.ac. uk/media/images-by-section/departments/research-centres-andunits/research-centres/centre-for- the-study-of-invention/deleuze_spinoza_affect.pdf (accessed 21 October 2016).

Dikeç, M (2015) Space, Politics and Aesthetics. Edinburgh University Press.

Ehrkamp P and Nagel C (2012) Immigration, places of worship and the politics of citizenship in the US South. Transactions of the Institute of British Geographers 37(4): 624-638.

Eng D (2001) Racial Castration: Managing Masculinity in Asian America. Durham: Duke University Press.

Ferguson M (2012) Sharing Democracy. New York: Oxford University Press.

Fincher R and Jacobs JM (eds) (1998) Cities of Difference. New York: Guilford Press.

Fuh Teh M (ed) (2012) A-Men. Available at: https://issuu.com/aconhealth/docs/a-men_magazine (accessed 21 October 2016).

Fung R (1991) Looking for my penis: The eroticized Asian in gay video porn. In: Bad Objectchoices (ed.) How Do I Look? Queer Film \& Video. Seattle: Bay Press, pp. 145-168.

Gilmore RW (2002) Fatal couplings of power and difference: Notes on racism and geography. The Professional Geographer 54(1): 15-24.

Gorman-Murray A and Hopkins P (eds) (2014) Masculinities and Place. Burlington: Ashgate. 
Gorman-Murray A and Nash C (2014) Mobile places, relational spaces: Conceptualizing change in Sydney's LGBTQ neighborhoods. Environment and Planning D: Society and Space 32(4): 622-641.

Gorman-Murray A and Waitt G (2009) Queer-friendly neighbourhoods: Interrogating social cohesion across sexual difference in two Australian neighbourhoods. Environment and Planning $A$ 41(12): 2855-2873.

Hage G (1998) White Nation: Fantasies of White Supremacy in a Multicultural Society. New York: Routledge.

Hall SM (2015) Migrant urbanisms: Ordinary cities and everyday resistance. Sociology 49(5): 853-869.

Haritaworn J (2015) Queer Lovers and Hateful Others: Regenerating Violent Times and Places. London: Pluto.

Hemming PJ (2011) Meaningful encounters? Religion and social cohesion in the English primary school. Social \& Cultural Geograpby 12(1): 63-81.

Hitchings R (2012) People can talk about their practices. Area 44(1): 61-67.

Holland SP (2012) The Erotic Life of Racism. Durham: Duke University Press.

Hopkins P (2014) Managing strangerhood: Young Sikh men's strategies. Environment and Planning A 46(7): 1572-1585.

Hopkins P and Noble G (2009) Masculinities in place: Situated identities, relations and intersectionality. Social \& Cultural Geography 10(8): 811-819.

Kallio KP (2012) Political presence and the politics of noise. Space and Polity 16(3): 287-302.

Kobayashi A and Preston V (2014) Being CBC: The ambivalent identities and belonging of Canadian- born children of immigrants. Annals of the Association of American Geographers 104(2): 234 242.

Kojima D (2014) Migrant intimacies: Mobilities-in-difference and basue tactics in queer Asian diasporas. Anthropologica 56(1): 33-44.

La Fountain-Stokes L (2011) Gay shame, Latina-and Latino-style: A critique of White queer performativity. In: Hames-García M and Javier Martínez E (eds) Gay Latino Studies: A Critical Reader. Durham: Duke University Press, pp. 55-80.

Laurier E and Philo C (2006) Cold shoulders and napkins handed: Gestures of responsibility. Transactions of the Institute of British Geographers 31(2): 193-207.

Lawson V and Elwood S (2014) Encountering poverty: Space, class, and poverty politics. Antipode 46(1): 209-228. 
Leitner H (2012) Spaces of encounters: Immigration, race, class, and the politics of belonging in small- town America. Annals of the Association of American Geographers 102(4): 828-846.

Lim J (2010) Immanent politics: Thinking race and ethnicity through affect and machinism. Environment and Planning A 42(10): 2393.

Lobo M (2014a) Everyday multiculturalism: Catching the bus in Darwin, Australia. Social \& Cultural Geography 15(7): 714-729.

Lobo M (2014b) Affective energies: Sensory bodies on the beach in Darwin, Australia. Emotion, Space and Society 12: 101-109.

Manalansan MF (2005) Race, violence, and neoliberal spatial politics in the global city. Social Text 23(3-4): 141-155.

Marshall D (2013) 'All the beautiful things': Trauma, aesthetics and the politics of Palestinian childhood. Space and Polity 17(1): 53-73.

Martin F, Healy C, Iwabuchi K, et al. (2015) Australia's 'Asian century': Time, space, and public culture. The Asia-Pacific Journal: Japan Focus 13(6): 1-15.

Matejskova T and Leitner H (2011) Urban encounters with difference: The contact hypothesis and immigrant integration projects in eastern Berlin. Social \& Cultural Geography 12(7): 717-741.

Matheson J (2012) I'm a sexual racist. Sydney Star Observer. Available at: http://www.starobserver. com.au/opinion/soapbox-opinion/im-a-sexual-racist/91678 (accessed 21 October 2016).

Mayblin L, Valentine G and Andersson J (2016) In the contact zone: Engineering meaningful encounters across difference through an interfaith project. The Geographical Journal 182(2): 213-222.

Mayblin L, Valentine G, Kossak F, et al. (2015) Experimenting with spaces of encounter: Creative interventions to develop meaningful contact. Geoforum 63: 67-80.

Muñoz JE (2009) Cruising Utopia: The Then and There of Queer Futurity. New York: New York University Press.

Nagel C and Hopkins P (2010) Introduction: Spaces of multiculturalism. Space and Polity 14(1): 1-11.

Nash CJ and Bain A (2007) 'Reclaiming raunch'? Spatializing queer identities at Toronto women's bathhouse events. Social \& Cultural Geography 8(1): 47-62.

Nayak A (2010) Race, affect, and emotion: Young people, racism, and graffiti in the postcolonial English suburbs. Environment and Planning A 42(10): 2370-2392.

Nguyen TH (2014) A View from the Bottom: Asian American Masculinity and Sexual Representation. Durham: Duke University Press. 
Nicoll F (2002) From Diggers to Drag Queens: Configurations of Australian National Identity. Pluto Press.

Noble G and Poynting S (2010) White lines: The intercultural politics of everyday movement in social spaces. Journal of Intercultural Studies 31(5): 489-505.

Noble G and Tabar P (2014) 'I am lord,... I am local': Migrant masculinity, sex and making yourself at home. In: Gorman-Murray A and Hopkins P (eds) Masculinities and Place. Burlington: Ashgate, pp. $77-92$.

Oswin N (2010) The modern model family at home in Singapore: A queer geography. Transactions of the Institute of British Geographers 35(2): 256-268.

Panagia D (2010) "Partage du sensible": The distribution of the sensible. In: Deranty J-P (ed.) Jacques Rancière: Key Concepts. Durham: Acumen Press, pp. 95-103.

Raj S (2011) Grindring bodies: Racial and affective economies of online queer desire. Critical Race and Whiteness Studies 7(2): 1-12.

Rancière J (2010) Dissensus: On Politics and Aesthetics. New York: Continuum.

Ridge D, Hee A and Minichiello V (1999) "Asian" men on the scene: challenges to "gay communities". Journal of Homosexuality 36(3-4): 43-68.

Riggs DW (2013) Anti-Asian sentiment amongst a sample of white Australian men on gaydar. Sex Roles 68(11-12): 768-778.

Rogaly B (2015) Disrupting migration stories: Reading life histories through the lens of mobility and fixity. Environment and Planning D: Society and Space 33(3): 528-544.

Ruez D (2016) Working to appear: The plural and uneven geographies of race, sexuality, and the local state in Sydney, Australia. Environment and Planning D: Society and Space 34(2): 282-300.

Saldanha A (2007) Psychedelic White: Goa Trance and the Viscosity of Race. Minneapolis: University of Minnesota Press.

Sandercock L (2003) Cosmopolis II: Mongrel Cities of the 21st Century. Continuum.

Schuermans N (2013) Ambivalent geographies of encounter inside and around the fortified homes of middle class whites in Cape Town. Journal of Housing and the Built Environment 28(4): 679-688.

Secor A (2010) Social surveys, interviews, and focus groups. In: Gomez B and Jones JP (eds) Research Methods in Geography. Malden: Wiley-Blackwell, pp. 194-205.

Sexual Racism Sux (n.d.) Sexual Racism Sux! Available at: https://sexualracismsux.com (accessed 21 October 2016).

Slocum R (2008) Thinking race through corporeal feminist theory: Divisions and intimacies at the Minneapolis Farmers' Market. Social \& Cultural Geography 9(8): 849-869. 
Swanton D (2010a) Sorting bodies: Race, affect, and everyday multiculture in a mill town in northern England. Environment and Planning A 42(10): 2332.

Swanton D (2010b) Flesh, metal, road: Tracing the machinic geographies of race. Environment and Planning D: Society and Space 28(3): 447.

Taylor Y and Falconer E (2015) 'Seedy bars and grotty pints': Close encounters in queer leisure spaces. Social \& Cultural Geography 16(1): 43-57.

Valentine G (2008) Living with difference: Reflections on geographies of encounter. Progress in Human Geography 32(3): 323-337.

Valentine G (2010) Prejudice: Rethinking geographies of oppression. Social \& Cultural Geography 11(6): 519-537.

Valentine G, Piekut A and Harris C (2015) Intimate encounters: The negotiation of difference within the family and its implications for social relations in public space. The Geographical Journal 181(3): 280-294.

Valentine G and Sadgrove J (2012) Lived difference: A narrative account of spatiotemporal processes of social differentiation. Environment and Planning A 44(9): 2049-2063.

Valentine G and Sadgrove J (2014) Biographical narratives of encounter: The significance of mobility and emplacement in shaping attitudes towards difference. Urban Studies 51(9): 1979-1994.

Valentine G and Waite L (2012) Negotiating difference through everyday encounters: The case of sexual orientation and religion and belief. Antipode 44(2): 474-492.

Vertovec S (2007) Super-diversity and its implications. Ethnic and Racial Studies 30(6): 1024-1054.

Waitt G (2006) Boundaries of desire: Becoming sexual through the spaces of Sydney's 2002 Gay Games. Annals of the Association of American Geographers 96(4): 773-787.

Waitt G and Johnson L (2013) 'It doesn't even feel like it's being processed in your head': Lesbian affective home journeys to and within Townsville, Queensland, Australia. In: Gorman-Murray A, Pini B and Bryant L (eds) Sexuality, Rurality and Geography. Lanham, MD: Lexington, pp. 143-158.

Wilson HF (2011) Passing propinquities in the multicultural city: The everyday encounters of bus passengering. Environment and Planning A 43(3): 634.

Wilson HF (2013) Learning to think differently: Diversity training and the 'good encounter'. Geoforum 45: 73-82.

Wilson HF (2014) Multicultural learning: Parent encounters with difference in a Birmingham primary school. Transactions of the Institute of British Geographers 39(1): 102-114. 
Wilson HF (2016) On geography and encounter Bodies, borders, and difference. Progress in Human Geography. DOI: 10.1177/0309132516645958.

Winders J and Schein R (2014) Race and diversity: What have we learned? The Professional Geographer 66(2): 221-229.

Wise A (2005) Hope and belonging in a multicultural suburb. Journal of Intercultural Studies 26(1-2): 171-186.

Wise A (2010) Sensuous multiculturalism: Emotional landscapes of inter-ethnic living in Australian suburbia. Journal of Ethnic and Migration Studies 36(6): 917-937.

Wise A and Velayutham S (eds) (2009) Everyday Multiculturalism. London: Palgrave Macmillan.

Wong S (2015) Defining 'Asian Australian' in the 'Asian century'. Peril. Available at: http://peril.com. au/topics/defining-asian-australian-in-the-asian-century/ (accessed 21 October 2016).

Woo A (2008) The fire of Andy Quan, an Asian-Canadian writer. Rice Paper: The Magazine of Asian Arts and Culture. Available at: http://ricepapermagazine.ca/2008/10/fire-of-andy-quan// (accessed 21 October 2016).

Ye J (2016a) Spatialising the politics of coexistence: Gui ju (规矩) in Singapore. Transactions of the Institute of British Geographers 41(1): 91-103.

Ye J (2016b) The ambivalence of familiarity: Understanding breathable diversity through fleeting encounters in Singapore's Jurong West. Area 48(1): 77-83.

Yue A (2008) Gay Asian sexual health in Australia: Governing HIV/AIDS, racializing biopolitics and performing conformity. Sexualities 11(1-2): 227-244. 